\title{
KUALITAS HIDUP DITINJAU DARI HARAPAN PADA PASIEN WANITA PENDERITA KANKER
}

\author{
David Junovandy ${ }^{1}$, Rianda Elvinawanty ${ }^{2}$, Winida Marpaung ${ }^{3}$ \\ ${ }^{1,2,3}$ Fakultas Psikologi Universitas Prima Indonesia \\ e-mail: ${ }^{1}$ davidjunovandy@gmail.com
}

\begin{abstract}
Abstrak. Jumlah pasien kanker di Indonesia selalu meningkat setiap tahunnya. Pada pasien kanker sering ditemukan permasalahan fisik, psikologis, relasi sosial, dan lingkungan. Penelitian ini bertujuan untuk mengetahui hubungan antara harapan dengan kualitas hidup pada pasien wanita penderita kanker. Hipotesis yang diajukan adalah terdapat hubungan positif antara harapan dengan kualitas hidup. Subjek penelitian dalam penelitian ini adalah pasien wanita penderita kanker di Murni Teguh Memorial Hospital sebanyak 136 orang yang dipilih dengan metode purposive sampling. Teknik analisis data yang digunakan dalam penelitian ini adalah Pearson Product Moment Correlation dengan bantuan program SPSS 19.00 for Windows. Hasil analisis data menunjukkan koefisien korelasi sebesar 0.712 ( $\mathrm{p}<0.001)$. Hasil ini menunjukkan terdapat hubungan positif yang signifikan antara harapan dengan kualitas hidup. Temuan ini dapat digunakan oleh pasien kanker sebagai dasar peningkatan kualitas hidup dimana pasien kanker perlu menumbuhkan harapan. Pasien kanker yang memiliki aspek psikologis positif seperti harapan dapat menangguhkan pasien dalam memandang kehidupannya.
\end{abstract}

Kata kunci: harapan, kualitas hidup, pasien kanker, wanita

\begin{abstract}
The case of cancer patients in Indonesia increases in every year. Patients often found physical, psychological, social relationship, and environmental problems. This study aims to find relationship between hope and quality of life. The hypothesis proposed is that there is a positive relationship between hope and quality of life. The subjects of this study were women patients who suffering cancer in Murni Teguh Memorial Hospital consisting of 136 patients selected by using purposive sampling method. The data analysis technique used in this study is the Pearson Product Moment Correlation through the help of SPSS 19.00 for Windows. The results of data analysis showed a correlation coefficient of $0.712(\mathrm{p}<0.001)$. It showed that there is a positive relationship between hope and quality of life. These findings can be used by cancer patients as a basis for improving the quality of life, cancer patients need to increase hope. Patients who have positive psychological aspects such as the hope could make patients have a good perspective at their lives.
\end{abstract}

Keywords: hope, quality of life, cancer patient, women 
Sehat merupakan keinginan setiap orang tanpa terkecuali. Namun, dalam rentang kehidupan manusia, manusia juga tidak luput dari berbagai macam penyakit, baik penyakit yang ringan hingga penyakit yang berat dan mematikan. Organisasi Kesehatan Dunia (dalam Diatmi \& Fridari, 2012) mendefinisikan sehat sebagai suatu keadaan fisik, mental, dan kesejahteraan sosial yang lengkap, bukan hanya ketiadaan penyakit atau kelemahan. Namun, perubahan gaya hidup dapat berdampak pada perubahan kesehatan manusia, terutama pada imunitas tubuhnya. Salah satu penyakit dari gaya hidup yang tidak sehat adalah kanker.

Kementerian Kesehatan RI (2015) menyatakan kanker merupakan salah satu penyebab kematian utama di seluruh dunia. Menurut Yayasan Kanker Indonesia (www.yayasankankerindonesia.org), kanker adalah penyakit akibat pertumbuhan tidak normal dari sel-sel jaringan tubuh yang berubah menjadi sel kanker. Senada dengan hal tersebut, Kelvin dan Tyson (2011) juga menyatakan bahwa kanker dimulai dengan perubahan struktur dan fungsi sel yang menyebabkan sel membelah dan berkembang biak tak terkendali. Sel selanjutnya dapat menyerang dan menyebabkan kerusakan jaringan di sekitarnya, melepaskan diri, dan menyebar ke bagian tubuh lainnya.

Data yang dihimpun oleh GLOBOCAN tahun 2012 menunjukkan bahwa jumlah kematian akibat kanker telah mencapai 8,2 juta kematian dari seluruh jenis kanker yang ada (Kementerian Kesehatan RI, 2015). Kanker dapat ditemukan baik pada pria maupun wanita. Secara khusus, pada pasien kanker wanita, perubahan fisik akibat kanker dapat terlihat secara kasat mata. Perubahan fisik ini dapat berupa bentuk dari pengobatan, seperti operasi pengangkatan payudara pada wanita penderita kanker payudara atau yang lebih dikenal dengan istilah mastectomy. Perubahan fisik lainnya juga dapat berupa pengangkatan rahim pada pasien kanker endometrium.

Permasalahan tersebut menunjukkan adanya permasalahan kualitas hidup pada pasien kanker, khususnya pada pasien wanita di aspek fisik, psikologis, hubungan sosial, dan lingkungan. Hal ini mendorong peneliti untuk melakukan survei pada pasien wanita penderita kanker di Murni Teguh Memorial Hospital Medan. Berdasarkan survei yang telah peneliti lakukan, peneliti mendapati para pasien wanita penderita kanker memandang kehidupannya dengan cara yang berbeda setelah diagnosis kanker ditegakkan. Mereka mengaku berputus asa, merasa berdosa, dan khawatir akan kehidupan mereka. Sebagian dari mereka juga merasa semakin dekat dengan kematian, khawatir tentang kehidupan rumah tangganya setelah ia sakit, dan mencemaskan masa depan anak-anak mereka. Para pasien kanker ini juga tak jarang memiliki permasalahan dengan body image mereka karena salah satu payudara mereka harus diangkat untuk mencegah kankernya bermetastase. Bahkan, demi mendapatkan pengobatan, mereka juga harus membayar nominal yang tidak sedikit. Biaya pemeriksaan medis, kemoterapi, radioterapi, pembedahan, dan obat-obatan yang mereka konsumsi tidak berkisaran pada nominal kecil. Hal ini yang juga menjadi beban finansial bagi para pasien kanker dan keluarga tentunya.

Berdasarkan survei yang telah peneliti lakukan, dapat disimpulkan bahwa para pasien wanita penderita kanker memiliki kualitas hidup yang rendah. Rendahnya kualitas hidup para pasien wanita penderita kanker ditandai dengan banyaknya gangguan fisik yang mereka rasakan setelah menderita kanker. Mereka mengaku setelah menjalani proses kemoterapi, mereka merasakan mual dan muntah yang hebat. Secara psikologis, banyak 
dari mereka belum mampu menerima kondisi mereka dengan penyakit ini. Mereka mengaku bahwa mereka menjadi sulit tidur dan lebih banyak berpikir tentang kematian yang menghantui mereka. Permasalahan hubungan sosial pun mereka rasakan, mereka mengaku menjadi lebih terbatas dalam berkomunikasi dengan keluarga dan teman-teman mereka. Hal ini terjadi karena terbatasnya energi dan stamina yang mereka miliki. Selain itu, mereka juga perlu menjaga kondisi tubuh mereka yang rentan tertular penyakit setelah kemoterapi karena imunitas yang menurun. Aspek lingkungan juga dapat memengaruhi kualitas hidup pasien wanita penderita kanker, yang paling mereka khawatirkan adalah kondisi finansial keluarga yang terguncang karena biaya pengobatan kanker tidaklah murah. Hal-hal tersebut menunjukkan rendahnya kualitas hidup pasien wanita penderita kanker.

Organisasi Kesehatan Dunia (dalam Diatmi \& Fridari, 2012) menyatakan kualitas hidup adalah persepsi dari individu dalam kehidupan meliputi konteks budaya dan sistem nilai dimana mereka hidup dalam kaitannya dengan nilai-nilai, standar, dan kekhawatiran dalam hidup. Bowling (dalam Prastiwi, 2012) berpendapat bahwa kriteria kualitas hidup yang positif ditentukan oleh bagaimana seseorang dapat memiliki pandangan psikologis yang positif, memiliki kesejahteraan emosional, memiliki kesehatan fisik dan kesehatan mental yang baik, memiliki kemampuan fisik untuk melakukan hal-hal yang ingin dilakukan, memiliki hubungan yang baik dengan teman dan keluarga, berpartisipasi dalam kegiatan sosial dan rekreasi, tinggal dalam lingkungan yang aman dengan fasilitas yang baik, memiliki uang yang cukup, dan mandiri.

Primardi dan Hadjam (2010) dalam penelitian mereka yang menguji hubungan antara harapan dengan kualitas hidup pada orang dengan epilepsi menemukan adanya hubungan yang positif dan signifikan antara harapan dengan kualitas hidup. Seseorang yang memiliki harapan yang tinggi memiliki energi yang lebih untuk memotivasi diri berperan aktif dalam penyelesaian masalah dan terus berkembang. Soylu, dkk., (2016) juga mendapatkan hasil yang sama dimana terdapat hubungan positif dan signifikan antara harapan dengan kualitas hidup pada 55 pasien wanita penderita kanker payudara.

Seorang psikolog, Lazarus (dalam Howell \& Larsen, 2015) menuliskan bahwa harapan adalah percaya pada sesuatu yang positif, yang saat ini tidak berlaku dalam kehidupan seseorang, namun masih dapat terwujud. Menurut Snyder (2000) harapan dapat didefinisikan sebagai pemikiran yang diarahkan pada tujuan, di mana orang menilai kemampuan mereka untuk menghasilkan jalan yang dapat dikerjakan dengan tujuan (pemikiran mencapai tujuan), bersama dengan potensi mereka untuk memulai dan mempertahankan gerakan melalui jalur (pemikiran penentu perilaku).

Peneliti mencoba mengaitkan fenomena harapan dengan kualitas hidup yang dimiliki oleh pasien wanita penderita kanker. Kualitas hidup yang rendah dapat dimiliki oleh pasien kanker ketika diagnosis kanker ditegakkan. Para pasien kanker mengaku sempat merasa putus asa dan merasa semakin dekat dengan kematian. Perasaan putus asa ini menunjukkan rendahnya harapan pada pasien kanker tersebut.

Penelitian terdahulu yang menghubungkan harapan dengan kualitas hidup pernah dilakukan oleh Souza dan Kamble (2016) yang menemukan hubungan positif dan signifikan antara harapan dengan kualitas hidup pada 397 pasien kanker dewasa. Hal ini merefleksikan tingginya harapan pada pasien kanker berhubungan dengan kualitas hidup yang baik. Pasien kanker yang memiliki aspek positif seperti harapan dapat mendorong 
pasien memiliki ketangguhan dalam menghadapi penyakit yang membawa outcome medis yang lebih baik.

Berdasarkan uraian-uraian sebelumnya, maka peneliti tertarik untuk meneliti hubungan antara harapan dengan kualitas hidup pada pasien wanita penderita kanker di Murni Teguh Memorial Hospital. Adapun yang membedakan penelitian ini dengan penelitian terdahulu adalah karakteristik subjek dalam penelitian yang meliputi pasien wanita penderita kanker, baik itu kanker payudara, kanker serviks, kelenjar getah bening, kanker rahim, dan lainnya, guna mendapatkan gambaran kualitas hidup pasien wanita penderita kanker yang lebih luas dibanding spesifik pada satu jenis kanker saja. Tujuan dari penelitian ini untuk mengetahui hubungan antara harapan dengan kualitas hidup. Manfaat praktis yang diharapkan dari penelitian ini jika hipotesis diterima adalah dibentuknya hope group support yang mana terdiri dari para pasien yang telah dinyatakan sembuh dan setiap relawan yang dapat berkomitmen untuk mendorong dan memotivasi para pasien kanker untuk menumbuhkan harapan sehingga kualitas hidup mereka dapat lebih baik. Hipotesis yang diajukan dalam penelitian ini adalah terdapat hubungan positif dan signifikan antara harapan dengan kualitas hidup. Dengan asumsi semakin tinggi harapan maka semakin tinggi kualitas hidup subjek penelitian demikian pula sebaliknya, semakin rendah harapan pada subjek maka semakin rendah kualitas hidupnya.

\section{METODE}

Penelitian ini menggunakan metode penelitian kuantitatif dengan teknik analisis korelasional. Siswanto, dkk., (2017) menjelaskan penelitian korelasional sebagai teknik pengelolaan data dengan cara mengorelasikan atau menghubungkan dua data variabel atau lebih untuk mengetahui tingkat keeratan hubungan. Penelitian ini bertujuan untuk mengungkapkan hubungan antara harapan dengan kualitas hidup.

Penelitian ini menggunakan 2 (dua) variabel, yaitu variabel bebas dan variabel terikat. Variabel bebas dalam penelitian ini adalah harapan dan variabel terikatnya adalah kualitas hidup. Harapan yang dimaksud dalam penelitian ini adalah gabungan dari keyakinan, keinginan, dan pemikiran yang berarah pada suatu tujuan yang bersifat positif dan pada saat ini belum dicapai namun masih dapat dicapai. Harapan pada subjek penelitian diukur dengan Skala Harapan yang peneliti kembangkan berdasarkan komponen-komponen harapan Snyder dan Lopez (2002) yang meliputi komponen goal, komponen pathway thinking, komponen agency thinking, dan komponen kombinasi pathway thinking dan agency. Semakin tinggi skor yang diperoleh subjek menunjukkan semakin tingginya harapan pada subjek. Semakin rendah skor yang diperoleh subjek menunjukkan semakin rendahnya harapan pada subjek. Kualitas hidup yang dimaksud dalam penelitian ini adalah evaluasi berdasarkan objektif dan/atau subjektif persepsi individu tentang posisinya dalam kehidupan dari keadaan fisik, kognitif, dan emosional, sehubungan dengan tujuan, harapan, standar, nilai, dan perhatiannya dalam konteks budaya dan sistem nilai dimana mereka hidup dan dalam kaitannya dengan nilai-nilai, standar, dan kekhawatiran dalam hidup. Kualitas hidup pada subjek penelitian diukur dengan Skala Kualitas Hidup yang peneliti kembangkan berdasarkan aspek-aspek kualitas hidup menurut WHOQOL-BREF (dalam Rapley, 2003) yang terdiri dari aspek kesehatan fisik, aspek psikologis, aspek hubungan sosial, dan aspek lingkungan. Peneliti 
menggunakan 4 respon alternatif jawaban untuk menghindari respon tengah demi meminimalisir permasalahan tendensi sentral.

Partisipan yang dilibatkan dalam penelitian ini dipilih dengan metode purposive sampling. Purposive sampling yaitu teknik penentuan sampel dengan pertimbangan tertentu (Sugiyono, dalam Siswanto, dkk., 2017). Pertimbangan yang ditetapkan adalah pasien wanita penderita kanker di Murni Teguh Memorial Hospital Medan, berusia 20-45 tahun, sudah menikah, dan dapat berkomunikasi dengan baik. Jumlah subjek yang didapatkan sebanyak 136 pasien wanita penderita kanker.

Skala Harapan dan Skala Kualitas Hidup masing-masing terdiri dari 40 aitem sebelum dilakukan uji coba terpakai. Setelah dilakukan uji coba terpakai dengan teknik Corrected Item Total Correlation dengan bantuan program SPSS 19.0 for Windows, didapatkan 10 aitem gugur dan 30 aitem valid untuk Skala Harapan dan 5 aitem gugur dan 35 aitem valid untuk Skala Kualitas Hidup. Koefisien validitas butir yang valid pada Skala Harapan bergerak dari nilai 0,308-0,621. Reliabilitas Skala Harapan ditemukan sangat tinggi dengan $\alpha=0.917$. Koefisien validitas butir yang valid untuk Skala Kualitas Hidup bergerak dari nilai 0,308-0,630. Reliabilitas Skala Kualitas Hidup dengan $\alpha=0.912$. Hal ini menunjukkan daya diskriminasi aitem pada kedua skala tersebut sudah baik dan begitu pula dengan reliabilitasnya setelah dilakukan uji reliabilitas dengan teknik Alpha Cronbach dengan bantuan program SPSS 19.0 for Windows.

Sebelum dilakukan pengujian hipotesis dengan Pearson Product Moment Correlation, terlebih dahulu dilakukan uji asumsi klasik yang meliputi uji normalitas sebaran dengan rumus Kolmogorov Smirnov $Z$ dan uji linearitas hubungan dengan test linearity dalam program SPSS 19.00 for Windows agar kesimpulan yang ditarik tidak menyimpang dari kebenaran yang seharusnya ditarik (Hadi, dalam Siswanto, dkk., 2017).

\section{HASIL}

Uji normalitas sebaran dilakukan agar dapat mengetahui apakah setiap variabel penelitian telah tersebar secara normal atau tidak. Dengan uji Kolmogorov Smirnov Test ditemukan pada variabel harapan diperoleh koefisien $\mathrm{KS}-\mathrm{Z}=1.195$ dengan sig sebesar 0.115 untuk uji 2 (dua) arah. Karena hipotesis yang diajukan dalam penelitian ini bersifat 1 (satu) arah, maka sig 1 (satu) arah dari variabel harapan sebesar 0.058 ( $\mathrm{p}>0.05$ ), yang berarti bahwa data pada variabel harapan memiliki sebaran atau berdistribusi normal. Sedangkan pada pengujian normalitas sebaran yang dilakukan terhadap variabel kualitas hidup diperoleh koefisien KS-Z = 0.695 dengan sig sebesar 0.719 untuk uji 2 (dua) arah. Karena hipotesis yang diajukan dalam penelitian ini bersifat 1 (satu) arah, maka sig uji 1 (satu) arah dari variabel kualitas hidup sebesar $0.36(\mathrm{p}>0.05)$, yang berarti bahwa data pada variabel kualitas hidup memiliki sebaran atau berdistribusi normal.

Hasil yang diperoleh dari pengujian linearitas hubungan menunjukkan bahwa variabel harapan dan variabel kualitas hidup memiliki hubungan linear. Hal ini didapatkan dari nilai sig yang diperoleh yaitu $0.000 *$ maka $\mathrm{p}<0.05$, sehingga dapat disimpulkan bahwa harapan dan kualitas hidup memiliki hubungan linear dan telah memenuhi syarat untuk dilakukan analisis korelasi Pearson Product Moment Correlation. 
Tabel 1. Hasil Uji Hipotesis

\begin{tabular}{lccc}
\hline \multicolumn{1}{c}{ Variabel } & $\begin{array}{c}\text { Pearson } \\
\text { Correlation }\end{array}$ & Sig & $R$ Square \\
\hline $\begin{array}{l}\text { Harapan dan } \\
\text { Kualitas Hidup }\end{array}$ & $0.712 * *$ & 0.000 & 0.507 \\
\hline$* *$ signifikansi pada taraf 0.01 (1-tailed) & &
\end{tabular}

Berdasarkan hasil analisis korelasi antara harapan dengan kualitas hidup, diperoleh koefisien korelasi Pearson Product Moment sebesar 0.712** dengan sig sebesar $\mathrm{p}<0.001$. Hal ini menunjukkan bahwa adanya korelasi positif yang signifikan antara harapan dengan kualitas hidup sehingga dikategorikan hubungan yang kuat. Nilai $R$ Square sebesar 0.507 menunjukkan variabel harapan dapat memengaruhi kualitas hidup sebesar $50.7 \%$, sehingga selebihnya, $49.3 \%$ dipengaruhi oleh faktor lain yang tidak diteliti. Dari hasil perhitungan tersebut, maka hipotesis yang diajukan dalam penelitian ini menunjukkan ada hubungan positif dan signifikan antara harapan dengan kualitas hidup pada pasien wanita penderita kanker di Murni Teguh Memorial Hospital Medan, diterima.

Tabel 2. Perbandingan Data Mean Empirik dan Hipotetik

\begin{tabular}{lcc}
\hline \multirow{2}{*}{ Variabel } & \multicolumn{2}{c}{ Mean } \\
\cline { 2 - 3 } & Empirik & Hipotetik \\
\hline Harapan & 86.51 & 75 \\
\hline Kualitas Hidup & 99.09 & 87.5 \\
\hline
\end{tabular}

Hasil analisis untuk skala harapan diperoleh mean empirik > mean hipotetik yaitu 86.51>75 maka dapat disimpulkan bahwa harapan pada subjek penelitian lebih tinggi daripada populasi pada umumnya. Kemudian, hasil analisis untuk skala kualitas hidup diperoleh mean empirik > mean hipotetik yaitu 99.09>87.5 maka dapat disimpulkan bahwa kualitas hidup pada subjek penelitian lebih tinggi daripada populasi pada umumnya. 
Tabel 3. Kategorisasi Data

\begin{tabular}{|c|c|c|c|}
\hline Variabel & Kategori & Jumlah (n) & Persentase \\
\hline \multirow[t]{3}{*}{ Harapan } & Rendah & 1 & $0.7 \%$ \\
\hline & Sedang & 85 & $62.5 \%$ \\
\hline & Tinggi & 50 & $36.8 \%$ \\
\hline Jumlah & & 136 & $100 \%$ \\
\hline \multirow[t]{3}{*}{ Kualitas Hidup } & Rendah & 0 & $0 \%$ \\
\hline & Sedang & 94 & $69 \%$ \\
\hline & Tinggi & 42 & $31 \%$ \\
\hline Jumlah & & 136 & $100 \%$ \\
\hline
\end{tabular}

Berdasarkan pada tabel kategorisasi tersebut, dapat dilihat pada variabel harapan terdapat 1 subjek (0.7 persen) yang memiliki harapan rendah, terdapat 85 subjek (62.5 persen) yang memiliki harapan sedang, dan terdapat 50 subjek (36.8 persen) yang memiliki harapan tinggi. Sedangkan untuk variabel kualitas hidup, dapat dilihat bahwa tidak terdapat subjek ( 0 persen) yang memiliki kualitas hidup rendah, terdapat 94 subjek (69 persen) yang memiliki kualitas hidup sedang, dan terdapat 42 subjek (31 persen) yang memiliki kualitas hidup tinggi.

\section{DISKUSI}

Hasil penelitian ini menunjukkan adanya hubungan positif yang kuat dan signifikan antara harapan dengan kualitas hidup pada pasien wanita penderita kanker di Murni Teguh Memorial Hospital Medan. Hubungan yang positif ini menjelaskan semakin tinggi harapan pada pasien wanita penderita kanker, maka semakin tinggi juga kualitas hidup yang mereka miliki. Sebaliknya, semakin rendah harapan yang dimiliki pasien wanita penderita kanker, maka semakin rendah juga kualitas hidup yang mereka miliki. Sehingga, hipotesis yang diajukan dalam penelitian ini diterima.

Soylu, dkk., (2016) mendapatkan hasil hubungan positif dan signifikan antara harapan dengan kualitas hidup pada 55 pasien wanita penderita kanker payudara. Pada penelitian yang senada, Souza dan Kamble (2016) juga menemukan hubungan yang positif dan signifikan antara harapan dengan kualitas hidup pada 397 pasien kanker dewasa. Hal ini merefleksikan tingginya harapan pada pasien kanker berhubungan dengan kualitas hidup yang baik. Pasien kanker yang memiliki aspek positif seperti harapan dapat mendorong pasien memiliki ketangguhan dalam menghadapi penyakit yang membawa outcome medis yang lebih baik. Hasil penelitian lain yang mempertegas hasil hubungan positif antara harapan dengan kualitas hidup dilakukan oleh Li, dkk., (2016) yang dilakukan pada pasien bladder cancer menemukan harapan memiliki hubungan positif terhadap kualitas hidup pada 365 pasien bladder cancer.

Hasil penelitian ini sesuai dengan pendapat Sirgy (2002) yang menyatakan bahwa harapan dapat meningkatkan kualitas hidup. Senada dengan pendapat tersebut, kelompok World Health Organization of Quality of Life (dalam Preedy \& Watson, 2010) 
menjelaskan kualitas hidup sebagai persepsi seseorang tentang posisinya dalam kehidupan sehubungan dengan tujuan, harapan, standar, nilai, dan perhatiannya. Hal ini menunjukkan bahwa harapan individu dalam hidup dapat menentukan kualitas hidupnya.

Harapan terbesar setiap pasien kanker pada umumnya bertahap. Berdasarkan hasil yang diperoleh dari wawancara yang telah dilakukan, para pasien pada awalnya memiliki harapan agar setiap rasa sakit seperti nyeri dan denyut yang mereka rasakan dapat berkurang. Disarankan untuk para pasien kanker mengikuti anjuran dokter untuk setiap pengobatan. Misalnya dengan operasi pembedahan yang diperlukan pada pasien kanker payudara ataupun pada pasien kanker endometrium. Selanjutnya, para pasien mengaku berharap dapat beraktivitas seperti sebelum mereka sakit. Untuk mencapainya, disarankan kepada para pasien agar rutin mengonsumsi suplemen makanan maupun obat stamina sesuai dengan anjuran dokter guna menyuplai tambahan tenaga. Makan yang teratur dan dengan komposisi gizi yang seimbang mampu para pasien memiliki stamina yang lebih baik, tidak hanya itu, hasil cek lab klinik juga menunjukkan komponen darah yang lebih baik pada pasien yang memiliki diet sesuai dengan anjuran dokter. Perbaikanperbaikan kualitas fisik ini akan mendorong pasien memiliki perasaan-perasaan yang lebih baik jika dapat dicapai. Kualitas fisik yang baik akan mendorong para pasien kanker memiliki hubungan sosial yang lebih baik lagi.

Hubungan antara harapan dengan kualitas hidup tidak hanya dilakukan pada para pasien penderita kanker saja. Peneliti lain juga menguji hubungan antara kedua variabel tersebut pada pasien dengan penyakit terminal lainnya. Yadav (2010) dalam penelitian pada orang dengan HIV dan AIDS di Nepal telah menemukan bahwa harapan berkorelasi positif dengan kualitas hidup secara global dan semua domain kualitas hidup. Sedangkan pada penelitian yang dilakukan oleh Bluvol dan Ford-Gilboe (2004) pada 40 pasien penderita dan keluarga pasien penderita stroke menunjukkan adanya korelasi yang positif moderat antara harapan dengan kualitas hidup pada penderita stroke dan pada keluarga pasien penderita stroke. Hasil yang ditemukan adalah semakin tinggi harapan, maka semakin tinggi kualitas hidup pada pasien stroke dan sebaliknya, semakin rendah harapan, maka semakin rendah kualitas hidup pada pasien stroke.

Penelitian yang senada juga pernah dilakukan Wu (2011) terhadap 175 korban kriminalisasi yang mengalami trauma di Taiwan. Ia menemukan bahwa harapan secara signifikan berhubungan dengan kualitas hidup para korban kriminalisasi tersebut. Hubungan antara harapan dengan kualitas hidup juga pernah diteliti terhadap pada pasien post polio syndrome. Penelitian tersebut dilakukan oleh Shiri, dkk., (2012) dan mendapatkan hasil adanya hubungan positif dan signifikan antara harapan dengan kualitas hidup pada 60 pasien post polio syndrome.

Berdasarkan uraian-uraian tersebut, dapat disimpulkan bahwa harapan memiliki hubungan yang positif dengan kualitas hidup. Hubungan yang positif ini tidak hanya ditemukan pada pasien kanker saja, pada pasien dengan penyakit lain seperti HIV/AIDS, stroke, dan post polio syndrome juga didapatkan harapan berhubungan dengan kualitas hidup. Hal ini menunjukkan harapan berperan secara signifikan dalam memengaruhi kualitas hidup pada manusia.

Berdasarkan hasil kategorisasi skor pada variabel kualitas hidup, dapat dilihat bahwa tidak terdapat subjek ( 0 persen) yang memiliki kualitas hidup rendah, terdapat 94 subjek (69 persen) yang memiliki kualitas hidup sedang, dan terdapat 42 subjek (31 persen) 
yang memiliki kualitas hidup tinggi. Hal ini menunjukkan bahwa sebagian besar pasien wanita penderita kanker memiliki kualitas yang sedang dan tinggi. Tingginya skor kualitas hidup pada subjek penelitian ditunjukkan dengan data hasil penelitian yang menunjukkan para pasien kanker merasakan berkurangnya rasa mual dan muntah sehabis kemoterapi seiring berjalannya siklus kemoterapi. Mereka juga optimis akan sembuh setelah melihat beberapa pasien lain yang semakin baik dan prima kondisinya. Kondisi yang semakin prima membuat para pasien ini dapat beraktivitas sebagaimana sedia kala, mereka dapat berkunjung ke rumah sanak saudaranya maupun berkomunikasi via telepon dengan teman-temannya. Kondisi finansial sedikit terguncang namun mereka yang memiliki asuransi maupun BPJS Kesehatan merasa sedikit terbantu dalam hal pemeriksaan dan pengobatan karena Murni Teguh Memorial Hospital telah bekerja sama dengan BPJS Kesehatan demi mewujudkan masyarakat yang sehat. Hasil ini tentunya kurang sesuai dengan hasil survei awal. Hal ini mungkin terjadi karena kualitas hidup merupakan sebuah konstruk yang luas. Sehingga, pasien mendapatkan skor yang rendah pada salah satu aspek, namun pada dua atau tiga aspek lainnya, ia dapat memiliki skor yang tinggi.

Berdasarkan hasil kategorisasi skor pada variabel harapan terdapat 1 subjek (0.7 persen) yang memiliki harapan rendah, terdapat 85 subjek (62.5 persen) yang memiliki harapan sedang, dan terdapat 50 subjek (36.8 persen) yang memiliki harapan tinggi. Hal ini menunjukkan bahwa sebagian besar pasien wanita penderita kanker memiliki harapan yang sedang dan tinggi. Tingginya skor harapan pada subjek penelitian ditunjukkan dengan data hasil penelitian yang menunjukkan para subjek memiliki tujuan untuk sembuh dari penyakit yang mereka derita. Selain itu, mereka juga mengembangkan berbagai cara yang dapat mereka tempuh demi mencapai kesembuhan. Dari cara-cara tersebut, mereka yakin setidaknya terdapat beberapa cara untuk mencapai kesembuhan, baik dengan menjaga pola makan, mengikuti jadwal berobat yang telah ditetapkan dokter, konsultasi rutin, kemoterapi, radioterapi, dan lain-lain. Hasil ini tentunya juga kurang sesuai dengan survei awal dimana para pasien awalnya mengaku berputus asa ketika diagnosis kanker ditegakkan. Hal ini mungkin terjadi karena setelah menjalani beberapa kali siklus kemoterapi, pasien merasakan perbaikan kesehatan fisik yang signifikan dibarengi dengan pengakuan-pengakuan pasien kanker lain yang juga merasakan hal yang sama. Selain itu, Murni Teguh Memorial Hospital juga sering memberikan seminar awam dengan testimoni pasien kanker yang telah sembuh. Seminar awam tersebut dapat diikuti oleh siapapun, sehingga harapan untuk sembuh pada para pasien kanker tersebut pun meningkat.

Individu yang memiliki harapan tinggi memiliki tujuan dalam hidupnya, mampu mengembangkan suatu cara untuk mencapai tujuannya, dan memiliki keyakinan mampu untuk mencapai tujuannya melalui cara-cara yang ia kembangkan. Goal jangka pendek dan jangka panjang ini membuat individu memiliki optimisme yang tinggi untuk sembuh.

\section{SIMPULAN DAN IMPLIKASI}

Berdasarkan hasil penelitian yang telah diperoleh, dapat dipahami bahwa hipotesis yang diajukan dalam penelitian ini dapat diterima, dimana terdapat hubungan positif yang signifikan antara harapan dengan kualitas hidup pada pasien wanita penderita kanker di Murni Teguh Memorial Hospital Medan. Hal tersebut direfleksikan dari hasil koefisien 
korelasi Pearson Product Moment dengan $\mathrm{r}=0.712, \mathrm{p}<0.001$. Harapan yang tinggi pada pasien wanita penderita kanker dapat membantu mereka memiliki kualitas hidup yang tinggi dan sebaliknya rendahnya harapan pada pasien wanita penderita kanker juga dapat memprediksi kualitas hidup yang rendah. Harapan memberikan kontribusi sebesar 50.7\% terhadap kualitas hidup pada subjek penelitian dan $49.3 \%$ sisanya dipengaruhi oleh faktor lain yang tidak diteliti.

Implikasi penelitian ini bagi para pasien wanita penderita kanker agar dapat menumbuhkan harapan dengan belajar dari pengalaman pasien kanker lain yang telah sembuh, sehingga pemikiran pasien kanker dapat berfokus pada tujuan untuk mencapai kesembuhan. Hal ini akan mendorong motivasi pasien kanker dan keyakinan pribadi dalam diri pasien kanker bahwa mereka akan sembuh jika mengikuti segala pengobatan dan perawatan kesehatan yang akan memobilisasi proses perbaikan kualitas kesehatan fisik, psikis, maupun sosial pasien kanker.

Implikasi bagi para peneliti selanjutnya yang ingin meneruskan penelitian ini, diharapkan dapat meluaskan area penelitian, tidak hanya pada satu rumah sakit saja. Selain itu, dapat juga melibatkan para pasien kanker pria. Dalam operasionalnya, peneliti lain juga dapat melibatkan variabel bebas lainnya, misalnya optimisme, resiliensi, kesepian, psychological adjustment styles, dan lain-lain.

\section{REFERENSI}

Bluvol, A., \& Ford-Gilboe, M. (2004). Hope, Health Work, and Quality of Life in Families of Stroke Survivors. Journal of Advanced Nursing, 48 (4), 322-332.

Diatmi, K., \& Fridari, I. G. A. D. (2014). Hubungan antara Dukungan Sosial dengan Kualitas Hidup pada Orang dengan HIV dan AIDS (ODHA) di Yayasan Spirit Paramacitta. Jurnal Psikologi Udayana, 1, (2), 353-362.

Kementerian Kesehatan RI. (2015). Stop Kanker. Jakarta: Pusat Data dan Informasi Kementerian Kesehatan RI.

Kelvin, J. F. \& Tyson, L. B. (2011). 100 Questions \& Answers About Cancer Symptoms and Cancer Treatment Side Effects $2^{\text {nd }}$ Edition. USA: Jones \& Bartlett Publisher, LLC.

Li, M. Y., Yang, Y. L., \& Wang, L. (2016). Effects of Social Support, Hope, and Resilience on Quality of Life among Chinese Bladder Cancer Patients. Health and Quality of Life Outcomes, 14, (1), 1-9. DOI: 10.1186/s12955-016-0481-z.

Prastiwi, T. F. (2012). Kualitas Hidup Penderita Kanker. Developmental and Clinical Psychology, 1, (1), 21-27.

Preedy, V. R. \& Watson, R. R. (2010). Handbook of Disease Burdens and Quality of Life Measures. USA: Springer. 
Primardi, A. \& Hadjam, M. N. R. (2010). Optimisme, Harapan, Dukungan Sosial Keluarga, dan Kualitas Hidup Orang dengan Epilepsi. Jurnal Psikologi, 3,(2), 123133.

Rapley, M. (2003). Quality of Life Research A Critical Introduction. London: Sage Publications.

Shiri, S., Wexler, I. D., Feintuch, U., Meiner, Z., \& Schwartz, I. (2012). Post Polio Syndrome: Impact of Hope on Quality of Life. Disability \& Rehabilitation, 31, (10), 824-830.

Sirgy, M. J. (2002). The Psychology of Quality of Life. USA: Springer Science+Bussiness Media Dordrecht.

Siswanto, Susila, \& Suyanto. (2017). Metodologi Penelitian Kombinasi Kualitatif Kuantitatif Kedokteran dan Kesehatan. Klaten: Bossscript

Snyder, C. R. (2000). Handbook of Hope Theory, Measures. San Diego: Academic Press.

Snyder, C. R., \& Lopez, S. J. (2002). Handbook of Positive Psychology. USA: Oxford University.

Souza, A. D., \& Kamble, S. V. (2016). Silver Lining and Hope in Relation with The Quality of Life in Adult Cancer Patients. The International Journal of Indian Psychology, 3, 2, (1), 24-31.

Soylu, C., Babacan, T., Sever, A. R., \& Altundag, K. (2016). Patients' Understanding of Treatment Goals and Disease Course and Their Relationship with Optimism, Hope, and Quality of Life: A Preliminary Study among Advanced Breast Cancer Outpatients before Receiving Palliative Treatment. Support Care Center, 24, (8), 3481-3488. DOI: 10.1007/s00520-016-3182-6.

Vacek, K. R., Coyle, R.D., \& Vera, E. M. (2010). Stress, Self-Esteem, Hope, Optimism, and Well Being in Urban, Ethnic Minority Adolescents. Journal of Multicultural Counseling and Development, 38, 99-111.

Wu, H. C. (2011). The Protective Effects of Resilience and Hope on Quality of Life of The Families Coping with The Criminal Traumatisation of One of Its Members. Journal of Clinical Nursing, 20, 1906-1915. DOI: 0.1111/j.13652702.2010.03664.x

Yadav, S. (2010). Perceived Social Support, Hope, and Quality of Life of Persons Living with HIV/AIDS: a Case Study from Nepal. Quality of Life Research, 19, (2), 157166. DOI: $10.1007 / \mathrm{s} 11136-009-9574-\mathrm{z}$ 